\title{
Mensagem ecológica ao camarada Marx
}

\author{
Carta de Michael Löwy ${ }^{1}$
}

Resumo: a presente carta dialoga criticamente com o trabalho de Marx sobre o tema da ecologia. Apresenta os aspectos da teoria marxiana que podem ser mobilizados para a reflexão contemporânea sobre a destruição do meio ambiente avançada pelo capitalismo, bem como os aspectos questionáveis presentes na mesma teoria que dizem respeito às relações entre seres humanos e natureza.

Palavras-chave: Eco-socialismo; Natureza; Capitalismo.

${ }^{1}$ Diretor emérito de pesquisas do Centre National de la Recherche Scientifique (CNRS). Tradução de Marco Tobón e Fernando Matias de Siqueira. 
São Paulo, 5 de agosto 2018.

\section{Lieber citoyen Marx,}

Ich bitte Ihnen um Entschuldigung dass ich Ihnen in Portugiesisch schreibe: mein Deutsch ist nicht gut genug für ein so langer Brief...Ich weiß, wegen ihren ausgezeichneten Artikeln über Spanien (New York Daily Tribune, 1856) dass sie gut Spanish lesen. Ich hoffe das sie auch mein Portugiesisch verstehen werden².

Somos muitos os discípulos seus aqui no Brasil, caro amigo Marx. Talvez seja este o país no mundo onde mais existe o interesse por suas ideias. O senhor não imagina com que entusiasmo se leem, estudam e discutem seus escritos econômicos, filosóficos ou políticos! Eles se vendem como pãezinhos frescos e são avidamente devorados por professores, estudantes, colegiais, sindicalistas, lutadores sem Terra ou sem Teto, cristãos das comunidades de base, sem esquecer os militantes das várias tribos da esquerda. Se o senhor pudesse visitar este país, ficaria impressionado com a quantidade de pessoas que o tem como referência principal, para o pensamento e para a ação.

O senhor tinha mil vezes razão de denunciar o capitalismo como um sistema injusto, parasitário, irracional, opressor, perverso e desumano. Seus argumentos são ainda mais atuais hoje do que em seu tempo! Mas há algo novo: em nossa época, o século XXI, o capitalismo, além de tudo isto, é um sistema brutalmente destruidor, que ameaça a própria vida neste planeta. $\mathrm{O}$ processo de mudança climática, consequência das energias fósseis que nutrem o sistema desde sua origem, está levando a um processo de destruição do meio ambiente que coloca em perigo as condições para a vida humana na Terra. Precisamos acabar com o capitalismo antes que ele acabe conosco!

\footnotetext{
${ }^{2}$ Caro citoyen Marx, peço desculpas por escrever em português: meu alemão não é bom o suficiente para uma carta tão longa. Sei que o senhor lê bem em espanhol pelos seus excelentes artigos sobre a Espanha (New York Daily Tribune, 1856). Espero que entenda também meu português. [N.T.]
} 
Já em seus escritos a tendência do capitalismo a destruir a natureza está claramente descrita. Mas na época o processo estava apenas em seus inícios, portanto é normal que esta problemática não tenha ocupado um lugar central em suas análises. Hoje em dia as condições mudaram, não podemos pensar a luta contra o capitalismo sem colocar a questão ecológica no epicentro de nossa reflexão e de nossa ação.

Caro amigo Marx: somos alguns de seus seguidores, aqui no Brasil e no resto do mundo, que nos designamos como eco-socialistas, ecomarxistas ou eco-comunistas. Esta terminologia talvez o surpreenda: ela indica a importância decisiva que tomou a crise ecológica e, em particular, a dramática questão do aquecimento global na nossa análise do sistema capitalista e em nossa proposta de um comunismo para o século XXI. Para pensar estes novos desafios, suas obras são instrumentos indispensáveis, sem os quais não podemos dar conta do processo real e das alternativas possíveis. Mas precisamos também de novos conceitos, novas propostas, para enfrentar os novos desafios. Mas não foi assim que o senhor tratou os problemas novos que foram aparecendo em sua época?

Com sua permissão, amigo Marx, tentarei descrever, nesta mensagem, os aspectos de sua obra que nos inspiram e nos orientam a nós eco-marxistas, como uma preciosa bússola - assim como os argumentos que nos parecem discutíveis e problemáticos. Se me permito algumas críticas não é, obviamente, porque me considero mais competente ou mais revolucionário! É simplesmente porque vivo um século e meio mais tarde e tenho que tomar em conta a crise ecológica de nossa época.

Gostaria, antes de mais nada, de defendê-lo contra um monte de críticas que me parecem fora de propósito. Na verdade, há muitos autores que se proclamam da ecologia que criticam insistentemente seus escritos. Por exemplo, eles o descrevem como partidário de um humanismo conquistador, prometeico, que opõe o homem a natureza, fazendo dele "o amo e senhor do mundo natural". É verdade que 
no seu pensamento encontram-se muitas referências ao "controle", à “subordinação" ou ao “domínio" mesmo da natureza. Mas na verdade, tanto para o senhor como para o amigo Engels, estas expressões simplesmente se referem ao conhecimento das leis da natureza.

Estes ecologistas provavelmente nunca leram seus escritos de juventude, que se distinguem por uma visão do ser humano como ser natural, inseparável de seu ambiente natural. Por exemplo, nos Manuscritos de 1844, esta concepção é claramente afirmada:

[Dizer] Que a vida física e mental do homem está interconectada com a natureza não tem outro sentido senão que a natureza está interconectada consigo mesma, pois o homem é uma parte da natureza (MARX, 2004, p.84).

O senhor se declara humanista, mas define o comunismo como um humanismo que é, por sua vez, um "naturalismo ativo"; e acima de tudo, o concebe como a verdadeira solução "do antagonismo entre o homem e a natureza". Por conta da abolição positiva da propriedade, a sociedade humana se tornará "a verdadeira ressureição da natureza, o naturalismo realizado do homem e o humanismo da natureza levado a efeito" (MARX, 2004, p.107). Estes trechos não se ocupam diretamente do problema ecológico - e das ameaças sobre o ambiente - mas a lógica deste naturalismo permite uma aproximação da relação homens/ natureza que não seja unilateral.

Outro erro destes senhores ecologistas antimarxistas é a afirmação de que o senhor, seguindo Ricardo, atribui a origem de todo valor e toda riqueza ao trabalho humano e perde de vista a contribuição da natureza. Esta crítica deriva, obviamente, de um mal-entendido: o senhor utiliza a teoria do valor-trabalho para explicar a origem do valor de troca, no quadro do sistema capitalista. A natureza, por outro lado, participa na formação de verdadeira riqueza se apresentando não como valores de troca, mas sim como valores de uso. Esta tese está explicitamente ilustrada em sua Crítica do Programa de Gotha, contra as ideias de Lassalle e seus discípulos: 
O trabalho não é a fonte de toda riqueza. A natureza é a fonte dos valores de uso (e é em tais valores que consiste propriamente a riqueza material!), tanto quanto o é o trabalho, que é apenas a exteriorização de uma força natural, da força de trabalho humana (MARX, 2012, p. 24).

Outra acusação injustificada deste pessoal é que o senhor seria um partidário do produtivismo. Ora, ninguém denunciou tanto como o senhor a lógica capitalista de produção para a produção, a acumulação do capital, de ganâncias e de mercadorias como um bem em si mesmo. A mesma ideia do socialismo - ao contrário de sua miserável caricatura burocrática-éo de uma produção de valores deuso, de bens necessários para a satisfação de necessidades humanas. O objetivo supremo do progresso técnico para o senhor não é crescimento infinito de bens ("o ter"), mas sim a redução da jornada de trabalho e o crescimento do tempo livre ("o ser").

Por outro lado, querido amigo Marx, não posso deixar de formular uma crítica: é verdade que se encontra, em alguns de seus escritos, uma postura pouco crítica para com o sistema de produção criado pelo capital e uma tendência a fazer do "desenvolvimento das forças produtivas" o veículo principal do progresso. O texto canônico deste ponto de vista é o seu famoso Prólogo à Contribuição à crítica da Economia Política (1859), um de seus escritos mais marcados por certo evolucionismo, pela filosofia do progresso e por uma visão nada problematizada das forças produtivas:

Em uma certa etapa de desenvolvimento, as forças produtivas materiais da sociedade entram em contradição com as relações de produção existentes (...). De formas evolutivas das forças produtivas que eram, esas relações convertem-se em entraves. Abre-se, então, uma época de revolução social. (...) Uma sociedade jamais desaparece antes que estejam desenvolvidas todas as forças produtivas que possa conter (...) (MARX, 2008, p.47-48). 
Neste famoso fragmento, as forças produtivas aparecem como "neutras", e a revolução só tem por tarefa abolir as relações de produção que tem se tornado um "estorvo" para um desenvolvimento ilimitado de todas aquelas forças em marcha. Enquanto eco-marxista do século XXI, tenho que manifestar meu desacordo com esta formulação!

O fragmento seguinte, dos Grundrisses, é um bom exemplo da admiração pouco crítica que aparece, em alguns de seus escritos, pelo trabalho "civilizador" do capitalismo e pela sua instrumentalização da natureza:

Portanto, da mesma maneira que a produção baseada no capital cria, por um lado, a indústria universal - isto é, trabalho excedente, trabalho criador de valor -, cria também, por outro lado, um sistema da exploração universal das qualidades naturais e humanas (...). Dessa forma, é só o capital que cria a sociedade burguesa e a apropriação universal da natureza, bem como da própria conexão social pelos membros da sociedade. Daí a grande influência civilizadora do Capital; sua produção de um nível de sociedade em comparação com o qual todos os anteriores aparecem somente como desenvolvimentos locais da humanidade e como idolatria da natureza. Só então a natureza torna-se puro objeto para o homem, pura coisa da utilidade; deixa de ser reconhecida como poder em si; e o próprio conhecimento teórico das suas leis autônomas aparece unicamente como ardil para submetê-la às necessidades humanas, seja como objeto do consumo, seja como meio da produção (MARX, 2011, p.542).

Como eco-comunista brasileiro não posso deixar de exprimir minha admiração pela "idolatria da natureza" das comunidades indígenas das Américas, que estão na primeira linha do combate às multinacionais exploradoras do petróleo, das minas de ouro, dos oleodutos, da soja transgênica e outras destruidoras iniciativas da "civilização" capitalista. Se o senhor vivesse hoje, tenho certeza de que estaria ao lado destes lutadores (e lutadoras), como a heroica Berta Cáceres, assassinada em Honduras. O senhor sempre esteve do lado dos oprimidos e dos explorados! 
Caro amigo Marx, gosto muito de uma passagem sua em $A$ Ideologia alemã onde aparece a intuição do potencial destrutivo das forças produtivas:

No desenvolvimento das forças produtivas advém uma fase em que surgem forças produtivas e meios de intercâmbio que, no marco das relações existentes, causam somente malefícios e não são mais forças de produção, mas forças de destruição (maquinaria e dinheiro) (Marx, 2007, p.41).

Não sei se o senhor se referia aqui à destruição da natureza, mas é exatamente o que está acontecendo hoje.

O caráter destruidor do capitalismo é um tema que o senhor aborda, de forma magistral, em certas passagens d'O Capital, que concernem à agricultura. Aqui se esboça um verdadeiro problema ecológico e uma crítica radical aos desastres que resultam do produtivismo capitalista - crítica que constitui, até hoje, um ponto de partida essencial para o eco-marxismo (espero que o senhor já tenha se acostumado a este neologismo um pouco heterodoxo).

O que se descobre nestes textos seus é uma espécie de teoria da ruptura do metabolismo entre as sociedades humanas e a natureza, como resultado do produtivismo capitalista. O senhor partiu dos trabalhos do químico e agrônomo alemão Liebig o qual analisou "do lado negativo da agricultura moderna de um ponto de vista científico", sendo isto "um dos méritos imortais de Liebig" (MARX, 1984b, p.133).

A expressão de Riss des Stoffwechsels, ruptura ou rasgamento do metabolismo - ou das trocas materiais - aparece principalmente numa passagem do capítulo 47, "Gênese do sistema capitalista", no livro III de O Capital:

Por um lado, a grande propriedade rural reduz a população agrícola a um mínimo em decréscimo constante e lhe contrapõe uma população industrial em constante crescimento, amontoada em grandes cidades; gera, com isso, condições que provocam 
uma insanável ruptura (unheilbarer Riss) no contexto do metabolismo (Stoffwechsel) social, prescrito pelas leis naturais da vida, em decorrência da qual se desperdiça (verschleudert) a força da terra e esse desperdício é levado pelo contrário muito além das fronteiras do próprio país (Liebig). (...) Grande indústria e grande agricultura, exploradas industrialmente, atual conjuntamente. Se, originariamente, elas se diferenciam pelo fato de que a primeira devasta (verwüstet) e arruína mais a força de trabalho e por isso a força natural do homem, e a última, mais diretamente a força natural da terra, mais tarde, ao longo do desenvolvimento, ambas se dão as mãos, ao passo que o sistema industrial na zona rural também extenua os trabalhadores e, por sua vez, a indústria e o comércio proporcionam à agricultura os meios para o esgotamento da terra (MARX, 1986, p.266).

O senhor concentra-se na agricultura e o problema da devastação da terra, mas conecta esta pergunta com um princípio mais geral: a ruptura do sistema de troca material (Stoffwechsel) entre as sociedades humanas e o ambiente, em contradição com "as leis naturais da vida". Outros momentos importantes desta passagem são: A cooperação entre a indústria e a agricultura neste processo de ruptura, e a extensão do dano, por causa do comércio internacional numa escala global.

O senhor retoma o tema da ruptura do metabolismo também num fragmento do livro I d'O Capital: a conclusão do capítulo sobre a grande indústria e a agricultura. Como eco-marxista, acho muito importante a forma pela qual o senhor explicita a questão das devastações provocadas pelo capital no ambiente natural - assim como uma visão dialética das contradições do "progresso" induzido pelas forças produtivas:

Com a preponderância sempre crescente da população urbana que amontoa em grandes centros, a produção capitalista acumula, por um lado, a força motriz histórica da sociedade, mas perturba, por outro lado, o metabolismo (Stoffwechsel) entre homem e terra, isto é, o retorno dos componentes da terra consumidos pelo homem, sob forma de alimentos e vestuários, à terra, 
portanto, a eterna condição natural de fertilidade permanente (dauernder) do solo. Com isso, ela destrói simultaneamente a saúde física dos trabalhadores urbanos e a vida espiritual dos trabalhadores rurais. Mas, ao destruir as condições desse metabolismo, desenvolvidas espontaneamente, obriga-o, simultaneamente, a restaurá-lo de maneiras sistemática, como lei reguladora da produção social e numa forma adequada ao pleno desenvolvimento humano. (...) E cada progresso da agricultura capitalista não é só um progresso da arte de saquear o solo, pois cada progresso no aumento da fertilidade por certo período é simultaneamente um progresso na ruína das fontes permanentes dessa fertilidade. Quanto mais um país, como, por exemplo, os Estados Unidos da América do Norte, se inicia com a grande indústria como fundamento de seu desenvolvimento, tanto mais rápido esse processo de destruição. Por isso, a produção capitalista só desenvolve a técnica e a combinação do processo de produção social ao minar simultaneamente as fontes de toda a riqueza: a terra e o trabalhador (MARX, 1984b, p. 133).

Com este texto o senhor nos deu formidáveis argumentos para entender a crise ecológica: em primeiro lugar, a ideia de que o progresso pode ser destrutivo, um "progresso" na degradação e a deterioração do ambiente natural. O exemplo escolhido não é o melhor e parece limitado demais - a perda da fertilidade da terra -, porém deixa descoberta a questão mais geral do atentado aos meios naturais, às "condições naturais eternas", pela produção do sistema capitalista.

Por outro lado, a exploração e a degradação dos trabalhadores e da natureza são colocadas aqui em paralelo, como resultado da mesma lógica predatória, aquela da grande indústria e agricultura capitalistas. É um tema que muitas vezes retorna em O Capital, por exemplo, nesses fragmentos do capítulo sobre a jornada do trabalho:

a limitação do trabalho nas fábricas foi ditada pela mesma necessidade que levou à aplicação do guano nos campos ingleses. A mesma cega rapacidade, a qual, em um caso, esgotou a terra, em outro afetou pelas raízes a força vital da nação. (...) Mas em seu impulso cego, desmedido, em sua voracidade por mais-trabalho, 
o capital atropela não apenas os limites máximos morais, mas também os puramente físicos da jornada de trabalho. (...) Atinge esse objetivo encurtando a duração da força de trabalho, como um agricultor ganancioso que consegue aumentar o rendimento do solo por meio do saqueio da fertilidade do solo (MARX, 1984a, p.353, p.378-379) .

Esta associação direta entre a exploração do proletariado e a da natureza, a despeito de seus limites, abre um campo de reflexão sobre a articulação entre luta de classes e luta em defesa do meio ambiente, em um combate comum contra a dominação do capital.

Com estes textos o senhor coloca em evidencia a contradição entre a lógica imediata do capital e a possibilidade de uma agricultura "racional" fundada numa temporalidade mais cumprida e numa perspectiva duradoura e intergeracional que respeite o ambiente:

químicos agrícolas bem conservadores, como, por exemplo, Johnston, admitem que uma agricultura realmente nacional encontra por toda parte limitações insuperáveis na propriedade privada. (...) todo o espírito da produção capitalista, orientado para o ganho direto e imediato de dinheiro - contrapõem-se à agricultura, que deve operar com a totalidade das condições vitais constantes das gerações de seres humanos que se sucedem. As florestas constituem um exemplo flagrante disso, pois somente são exploradas às vezes, até certo ponto, de acordo com o interesse geral onde não são propriedade privada, mas estão submetidas à administração do Estado (MARX, 1986, p.125).

Esta questão da destruição das florestas é muitíssimo atual aqui no Brasil! O senhor a discute com frequência n'O Capital:

O desenvolvimento da agricultura e da indústria em geral mostrou-se (...) tão ativo na destruição das florestas que tudo o que, em face disso, tudo o que inversamente se fez para sua conservação e produção é uma grandeza completamente evanescente (MARX, 1985, p.183). 
Os dois fenômenos assinalados - a deterioração das florestas e da terra -, além disso, se liga diretamente nas suas análises.

Gostaria agora de conversar contigo, estimado amigo Marx, nesta carta que está ficando mesmo muito longa, sobre o programa socialista em relação ao meio ambiente. Que transformações do sistema produtivo devem ser realizadas para fazê-lo compatível com o cuidado da natureza? Será que se pode considerar a produção socialista simplesmente como a apropriação coletiva das forças e meios de produção desenvolvidos pelo capitalismo? Será que uma vez abolido o "obstáculo" que representam as relações de produção, e em particular as relações de propriedade, estas forças poderão se desenvolver sem estorvos? Haverá, então, uma espécie de continuidade substancial entre o aparato produtivo capitalista e o socialista, admitindo que a posição socialista seria, sobretudo, a gestão planificada e racional desta civilização material criada pelo capital?

Esta pareceria ser a posição que o senhor defende na célebre conclusão do capítulo sobre a acumulação primitiva do capital:

O monopólio do capital torna-se um entrave para o modo de produção que floresceu com ele e sob ele. A centralização dos meios de produção que floresceu com ele e sob ele. A centralização dos meios de produção e a socialização do trabalho atingem um ponto em que se tornam incompatíveis com seu invólucro capitalista. Ele é arrebentado. Soa a hora final da propriedade privada capitalista. (...) Mas a produção capitalista produz, com a inexorabilidade de um processo natural, sua própria negação (MARX, 1984b, p.381).

Querido Marx, peço desculpas, mas tenho que discordar aqui! Não é que eu seja pretensioso, simplesmente preciso considerar os argumentos do ponto de vista da dramática situação que temos que enfrentar no século XXI... É evidente que o senhor, no século XIX, não podia adivinhar esta nova conjuntura. O que me parece discutível nesta passagem - além do determinismo fatalista e positivista - é 
que ela parece deixar intacta, na perspectiva socialista, o conjunto do modo de produção criado "sob os auspícios" do capital, pondo em questão só a propriedade privada, que se torna um "estorvo" para o desenvolvimento dos recursos materiais da produção.

Felizmente, existem também muitos outros escritos seus que levam em conta a dimensão ecológica para o programa socialista e abrem algumas pistas muito importantes para o eco-socialismo. $\mathrm{O}$ fragmento citado do volume I de O Capital, o senhor permite entender que as sociedades pré-capitalistas asseguram espontaneamente (naturwüchsig) o metabolismo (Stoffwechsel) entre os grupos humanos e a natureza; no socialismo (a palavra não aparece diretamente, mas se pode inferir pelo contexto) deve restabelecer de forma sistemática e racional, "como lei reguladora da produção social". É uma pena que o senhor não teve tempo de desenvolver esta hipótese, fundada sobre a ideia de que as comunidades pré-capitalistas - nossos indígenas das Américas! - viveram espontaneamente em harmonia com seu habitat, e que a tarefa do socialismo é estabelecer esta harmonia com novas bases.

Em vários momentos de sua obra, sobretudo em O Capital, o senhor aparece como um autêntico precursor do eco-socialismo, insistindo que a conservação do ambiente natural é uma tarefa fundamental do socialismo. Por exemplo, o volume III d'O Capital opõe à lógica capitalista da grande produção agrícola, fundada na exploração e no esgotamento das forças da terra, a outra lógica, da natureza socialista:

Em ambas as formas, em lugar do cultivo racional e consciente do solo enquanto propriedade perene da comunidade, condição inalienável [unveräusserlichen] da existência e da reprodução da cadeia de gerações humanas que substituem umas as outras (MARX, 1986, p.265).

Um raciocínio análogo se descobre em algumas páginas mais para frente: 
Mesmo uma sociedade inteira, uma nação, mesmo todas as sociedades coevas em conjunto não são proprietárias da Terra. São apenas possuidoras, usufrutuárias dela, e como boni patres familias devem legá-la melhorada às gerações posteriores (MARX, 1986, p.239).

Finalmente, ainda no mesmo volume III de O capital, o senhor não define o socialismo como o "domínio" e o controle humano sobre a natureza, e sim como o controle das trocas materiais com a natureza: na esfera da produção material,

a liberdade só pode consistir em que o homem social, os produtores asociados, regulem racionalmente esse seu metabolismo [Stoffwechsel] com a Natureza, trazendo-o para seu controle comunitário, em vez de serem dominados por ele [ihm] como se fora por uma força cega (MARX, 1986, p.273).

Não seria difícil encontrar outros exemplos de uma real sensibilidade à questão do ambiente natural da atividade humana. Sem dúvida falta na sua obra uma perspectiva ecológica de conjunto, o que é inevitável para um pensador do século XIX. Por outro lado, é impossível pensar uma ecologia crítica à altura dos desafios contemporâneos sem levar em conta sua formidável crítica da economia política, que põe em questão a lógica destrutiva induzida pela acumulação ilimitada do capital.

Amigo Marx, uma ecologia que ignora ou despreza seus escritos e sua crítica ao fetichismo da mercadoria condena-se a ser não mais que um corretivo dos "excessos" do produtivismo capitalista.

A questão ecológica é para nós, eco-marxistas, o grande desafio para a renovação do pensamento revolucionário no umbral do século XXI. Ela exige uma ruptura radical com a ideologia do progresso linear e com o paradigma tecnológico e econômico da civilização industrial moderna. Certamente não se trata - como já foi assinalado na sua obra - de pôr em questão a necessidade do progresso científico 
e técnico, assim como da elevação da produtividade do trabalho: essas são condições fora de controvérsia para os objetivos essenciais do socialismo: a satisfação das necessidades sociais e a redução da jornada do trabalho. O desafio é reorientar o progresso para torná-lo compatível com a preservação do equilíbrio ecológico do planeta.

O calcanhar de Aquiles de alguns de seus textos mais conhecidos é uma concepção acrítica das forças produtivas capitalistas - quer dizer: do aparato técnico/produtivo capitalista/industrial moderno - como se elas fossem "neutras" e como se fosse suficiente para os revolucionários socializá-las, substituir sua apropriação privada por uma apropriação coletiva, para beneficiar assim aos trabalhadores operários e desenvolvê-las de maneira ilimitada.

Enquanto eco-marxista, penso que seria necessário aplicar ao aparato produtivo formado pelo capital o mesmo raciocínio que o senhor propôs em A guerra civil na França de 1871 para o aparato do Estado:

a classe operário não pode, como as facções rivais da classe apropriadora o fizeram em seus momentos de triunfo, simplesmente se apossar da maquinaria do Estado tal como ela se apresenta e emprega-la para seus próprios fins (MARX, 2013, p.182).

Mutatis mutandis, os trabalhadores não podem estar satisfeitos com tomar tal qual a "máquina" capitalista produtiva e fazê-la funcionar por sua própria conta: eles devem transformá-la radicalmente - o equivalente do que o senhor chama, em uma carta a Kugelmann sobre a Comuna de Paris, "romper o aparato de Estado" burguês em função de critérios socialistas e critérios ecológicos. O que não só implica a substituição de formas de energia destrutivas por fontes de energia renováveis e não contaminantes, como a energia solar, mas também uma transformação profunda do sistema produtivo herdado do capitalismo, assim como do sistema de transportes, do sistema do habitat urbano e do padrão de consumo insustentável. 
Em outras palavras: o eco-comunismo arrastra consigo uma radicalização da ruptura com a civilização material capitalista. Nesta perspectiva, o projeto revolucionário aponta não só para uma nova sociedade e para um novo modo de produção, mas também para um novo paradigma de civilização.

Posso estar enganado, caro amigo Marx, mas acho que se o senhor vivesse no século XXI, seria eco-comunista...

Agradeço muito sua paciência em ler esta longa carta. Qualquer comentário seu seria recebido com muito respeito e atenção.

Seu humilde discípulo, heterodoxo, mas fiel,

Michael Löwy. 


\section{Referências bibliográficas}

MARX, Karl. Manuscritos económico-filosóficos. São Paulo: Boitempo, 2004.

. Crítica do programa de Gotha. São Paulo: Boitempo, 2012.

. Contribuição à crítica da economia política. São Paulo: Expressão Popular.

. Grundrisse: manuscritos econômicos de 1857-1858: esboços da crítica da economia política. São Paulo: Boitempo, 2011.

- A ideologia alemã: crítica da mais recente filosofia alemã em seus representantes Feuerbach, B. Bauer e Stirner, e do socialismo alemão em seus diferentes profetas, 1845-1846. São Paulo: Boitempo, 2007.

- O capital: crítica da economia política. São Paulo: Abril Cultural, 1984a, livro I, tomo 1

- O capital: crítica da economia política. São Paulo: Abril Cultural, 1984b, livro I, tomo 2.

. O capital: crítica da economia política. São Paulo: Abril Cultural, 1985, livro II, tomo 2.

. O capital: crítica da economia política. São Paulo: Abril Cultural, 1986, livro III, tomo 2.

. A guerra civil na França. São Paulo: Boitempo, 2013. 